\title{
Prognostic value of microRNA- 126 and CRK expression in gastric cancer
}

\author{
This article was published in the following Dove Press journal: \\ OncoTargets and Therapy \\ II October 2016 \\ Number of times this article has been viewed
}

\section{Shun Yue ${ }^{1, *}$ \\ Huichang Shi ${ }^{2, *}$ \\ Jun $\operatorname{Han}^{3}$ \\ Tiecheng Zhang' \\ Weiguo Zhu' \\ Dahong Zhang'}

'Department of Medical Oncology, Huai'an First People's Hospital, Nanjing Medical University, Huai'an City, ${ }^{2}$ Department of Medical Oncology, The Second People's Hospital of Huai'an, Huai'an City, ${ }^{3}$ Department of Medical Oncology, Qinghai Province People's Hospital, Xining City, People's Republic of China

*These authors contributed equally to this work
Correspondence: Dahong Zhang Department of Medical Oncology, Huai'an First People's Hospital, Nanjing Medical University, 6 Beijing Road

West, Huai'an City, Huai'an 223300, People's Republic of China

Tel +86 I38 52496073

$\mathrm{Fax}+8651784922412$

Email zhangdahong73@I26.com
Background: MicroRNA (miR)-126, acting as a tumor suppressor, has been reported to inhibit the invasion of gastric cancer cells in part by targeting v-crk sarcoma virus CT10 oncogene homologue (CRK). The aim of this study was to investigate the clinical significance of miR$126 /$ CRK axis in gastric cancer.

Methods: miR-126 and CRK mRNA expression levels were detected by real-time quantitative reverse transcription polymerase chain reaction in 220 self-pairs of gastric cancer and adjacent noncancerous tissues.

Results: Expression levels of miR-126 and CRK mRNA in gastric cancer tissues were, respectively, lower and higher than those in adjacent noncancerous tissues (both $P<0.001$ ). Low miR-126 expression and high CRK expression, alone or in combination, were all significantly associated with positive lymph node and distant metastases and advanced TNM stage of human gastric cancer (all $P<0.05$ ). We also found that the overall survival rates of the patients with low miR-126 expression and high CRK expression were, respectively, shorter than those with high miR-126 expression and low CRK expression. Interestingly, miR-126-low/CRK-high expression was associated with a significantly worse overall survival of all miR-126/CRK groups $(P<0.001)$. Moreover, multivariate analysis identified miR-126 and/or CRK expression as independent prognostic factors for patients with gastric cancer. Notably, the prognostic relevance of miR-126 and/or CRK expression was more obvious in the subgroup of patients with TNM stage IV.

Conclusion: Dysregulation of miR-126/CRK axis may promote the malignant progression of human gastric cancer. miR-126 and CRK combined expression may serve as an independent predictor of overall survival in patients with advanced gastric cancer.

Keywords: miR-126, v-crk sarcoma virus CT10 oncogene homologue, prognosis, real-time quantitative polymerase chain reaction

\section{Introduction}

Gastric cancer ranks fourth in incidence (after lung cancer, breast cancer, and colorectal cancer) and second in mortality (after lung cancer) among all cancers in the world., ${ }^{1,2}$ In the People's Republic of China, gastric cancer constitutes approximately $33 \%$ of all worldwide cases of this disease. ${ }^{3,4}$ The recent development of diagnostic and surgical techniques has greatly improved the prognosis of gastric cancer patients. However, approximately two-thirds of patients have locally advanced or metastatic disease at diagnosis, and up to one-half of patients have recurrent disease after curative surgery. ${ }^{5-7}$ Thus, it is extremely necessary to have a better understanding of gastric carcinogenesis and identify novel and efficient prognostic and/or therapeutic tumor markers to improve current management and assist in the earlier diagnosis of gastric cancer.

MicroRNAs (miRNAs), a class of noncoding small molecular single-chain RNAs including 18-25 nucleotides, have highly conservative, temporal, and tissue-specific 
characteristics. ${ }^{8}$ They carry out various biological functions by repressing the expression of their target genes at the posttranslational level through base-pairing with endogenous mRNAs. ${ }^{9}$ Growing evidence shows that numerous miRNAs are aberrantly expressed in various human cancer types, and miRNA expression profiling has shown certain miRNAs to be associated with cancer development, progression, and response to therapy. ${ }^{10}$ Accumulating studies suggest that miRNAs have a close relationship with gastric carcinogenesis. ${ }^{1-16} \mathrm{miR}-$ 126 originates from a common precursor structure located at chromosome 9q34.3, the seventh intron of the epidermal growth factor-like domain 7 (EGFL7) gene. ${ }^{17}$ Its expression is regulated by EGFL 7 gene promoter and is generated by EGFL 7 pre-mRNA splicing. ${ }^{18,19}$ Growing evidence shows that miR-126 is frequently downregulated in a variety of malignancies and functions as a potential tumor suppressor. In gastric cancer, Feng et $\mathrm{al}^{20}$ in 2010 reported that miR-126 was significantly downregulated and its overexpression in SGC-7901 cells potently inhibited cell growth by inducing cell cycle arrest in G0/G1 phase, migration, and invasion in vitro as well as tumorigenicity and metastasis in vivo. They also identified the adaptor protein v-crk sarcoma virus CT10 oncogene homologue (CRK) as a target of miR-126. Otsubo et $\mathrm{al}^{21}$ in 2011 indicated that exogenous miR-126 overexpression could significantly enhance the anchorage-dependent and -independent growth of gastric cancer cell lines. Wang et $\mathrm{al}^{22}$ in 2013 revealed that miR-126 could negatively regulate CRKL mRNA which promoted cell proliferation in gastric cancer. Liu et $\mathrm{al}^{23}$ in 2014 found that miR-126 could suppress growth of SGC-7901 cells by synergistically targeting the oncogenes PI3KR2 and CRK and the tumor suppressor PLK2. In the same year, Li et $\mathrm{al}^{24}$ further revealed that overexpression of miR-126 inhibited gastric cancer cell invasion in part by targeting CRK. These findings suggest that miR-126/CRK axis may play an important role in gastric carcinogenesis. The aim of this study was to investigate the clinical significance of miR-126/CRK axis in human gastric cancer.

\section{Materials and methods}

The strategy of this study is shown in Figure 1.

\section{Patients and tissue samples}

This study was approved by the Research Ethics Committee of Nanjing Medical University (Huai'an, People's Republic of China). Written informed consent was obtained from all of the patients. All specimens were handled and made anonymous according to the ethical and legal standards.

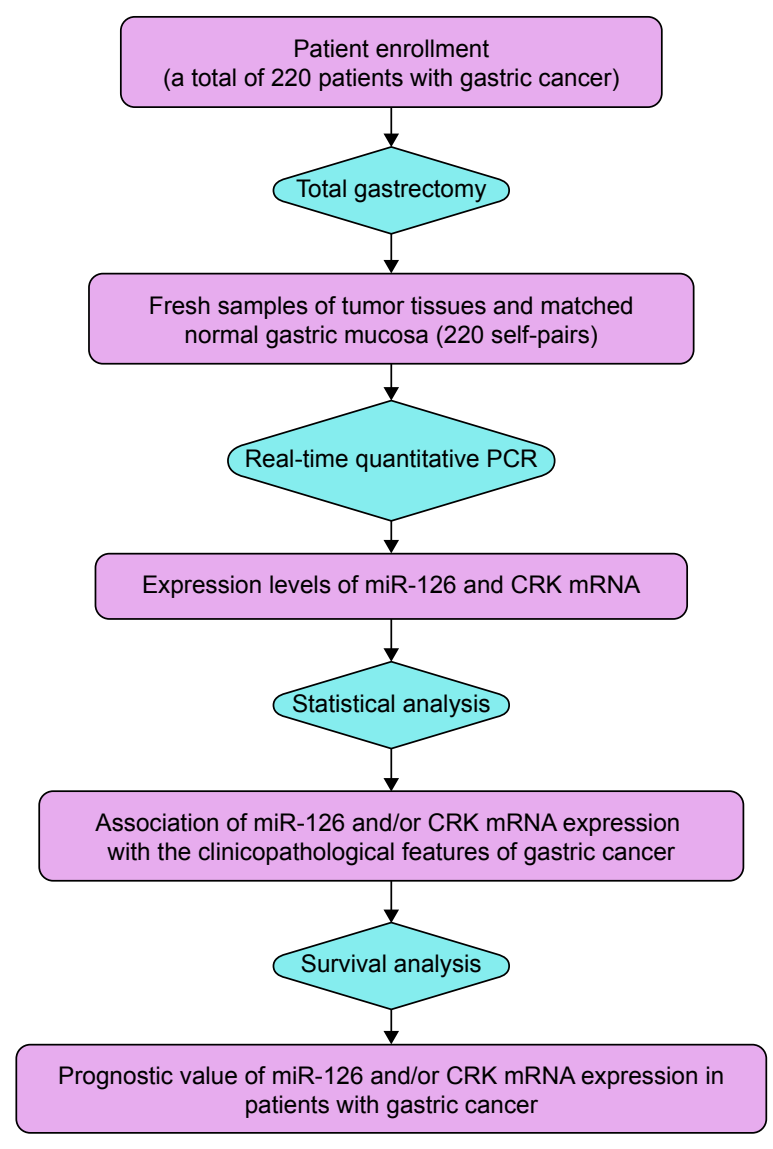

Figure I A flowchart of the current study.

Abbreviations: PCR, polymerase chain reaction; CRK, CTIO oncogene homologue.

For real-time quantitative reverse transcription polymerase chain reaction (PCR), 220 patients (160 men, 60 women; median age, 60.0 years; range, 29-88 years) were recruited from the Department of Oncology, First Hospital of Huai'an, Nanjing Medical University between January 2000 and January 2006. All underwent total gastrectomy. Fresh samples of tumor tissues and matched normal gastric mucosa were obtained immediately after gastric resection. Resected specimens were studied pathologically according to the criteria described in the Union for International Cancer Control (UICC) pTNM classification (2002). ${ }^{25}$ The clinicopathological characteristics of all 220 patients with gastric cancer enrolled in this study are summarized in Table 1. The samples were carefully dissected from resected specimens by a pathologist and immediately snap-frozen in separate vials, using liquid nitrogen. These frozen specimens were stored at $-80^{\circ} \mathrm{C}$ in a tumor bank before use.

All patients had follow-up records for more than 5 years. The follow-up deadline was December 2010. Overall survival was defined as the time from surgery until death by cancer or the last clinical assessment. 
Table I Clinicopathological features of all 220 patients with gastric cancer

\begin{tabular}{ll}
\hline Features & Number of cases (\%) \\
\hline Age (years) & \\
$\leq 55$ & $112(50.91)$ \\
$>55$ & $108(49.09)$ \\
Sex & \\
Male & $160(72.73)$ \\
Female & $60(27.27)$ \\
Tumor location & \\
Cardia & $30(13.64)$ \\
Body & $82(37.27)$ \\
Antrum & $108(49.09)$ \\
Differentiation degree & \\
Well differentiated & $40(18.18)$ \\
Moderately differentiated & $58(26.36)$ \\
Poorly differentiated & $122(55.45)$ \\
Depth of invasion & \\
TI/T2 & $71(32.27)$ \\
T3/T4 & $149(67.73)$ \\
Lymph node metastasis & \\
N0 & $42(19.09)$ \\
NI & $80(36.36)$ \\
N2 & $68(30.91)$ \\
N3 & $30(13.64)$ \\
Distant metastasis & $190(86.36)$ \\
M0 & $30(13.64)$ \\
MI & $65(29.55)$ \\
TNM stage & $15(6.82)$ \\
I & $20(9.09)$ \\
II & $120(54.55)$ \\
III & \\
\hline & \\
\hline &
\end{tabular}

\section{RNA extraction and real-time quantitative PCR}

miR-126 and CRK mRNA expression levels in 220 gastric cancer tissues and the matched normal gastric mucosa were detected by real-time quantitative PCR as described in our previous study. ${ }^{26} \mathrm{U} 6$ and GAPDH were, respectively, used as internal controls for the detection of miR-126 and CRK mRNA expression. Specific primers were designed for the reverse transcription: the primer sequences for miR-126 were TGG AAT GTA AGG AAG TGT GTG G, for U6 were GAA CGC TTC ACG AAT TTG C, and for CRK were ACA TGT TCC AAT ATG ATT CC. The primer sequences for PCR reaction were as follows: for miR-126, forward 5'-GGA ATG TAA GGA AGT GTG-3', reverse 5'-GAG CAG GCT GGA GAA-3'; for U6, forward 5'-CTT CGG CAG CAC ATA TAC-3', reverse 5'-GAA CGC TTC ACG AAT TTG C-3'; for CRK, forward 5'-AGG GTT ATC CAG AAG CGA GTC-3', reverse 5'-CTT CCC ACT GAC CAC TCA CAT-3'; and for GAPDH, forward $5^{\prime}$-ACA TGT TCC AAT ATG ATT CC-3', reverse 5'-TGG ACT CCA CGA CGT ACT CAG-3'. Each reaction was performed in triplicate, and the expression levels of miR-126 and CRK mRNA were both calculated as $2^{-\Delta \Delta \mathrm{Ct}}$, where $\Delta \mathrm{Ct}=\mathrm{Ct}$ (miR-126 or CRK mRNA) $-\mathrm{Ct}$ (U6 or GAPDH). In addition, the median values of miR-126 or CRK expression levels in gastric cancer tissues were, respectively, used as cutoff points to divide all 220 patients into miR-126high/low groups or CRK-high/low groups.

\section{Statistical analysis}

SPSS version 12.0 for Windows software (SPSS Inc., Chicago, IL, USA) and SAS 9.1 software (SAS Institute Inc., Cary, NC, USA) were used for statistical analysis. Measurement data were analyzed using Student's $t$-test, while categorical data were studied using the chi-square test or Fisher's exact test. Correlations between miR-126 and CRK mRNA expression were calculated using Spearman's correlation. Survival curves were estimated using the Kaplan-Meier method, and the log-rank test was used to calculate differences between the curves. Multivariate survival analyses were conducted by a Cox proportional hazards regression model to find the factors that affect the prognosis of gastric cancer. Differences were considered statistically significant when $P$ was less than 0.05 .

\section{Results}

\section{miR-I 26 and CRK mRNA expression levels were, respectively, decreased and increased in human gastric cancer tissues} miR-126 expression levels in gastric cancer tissues were significantly decreased (cancer vs normal: $1.79 \pm 0.79$ vs 3.90 $\pm 1.17 ; P<0.001$ ) (Figure 2A), while CRK mRNA expression levels in gastric cancer tissues were dramatically increased (cancer vs normal: $3.74 \pm 1.08$ vs $1.50 \pm 0.54 ; P<0.001$ ) (Figure 2B), compared with the matched normal gastric mucosa. According to our method of grouping, 34 in $220(15.45 \%)$ cases had high expression of both miR-126 and CRK, 40 in 220 (18.18\%) cases had low expression of both miR-126 and CRK, 68 in 220 (30.91\%) cases had miR-126-high and CRK-low expression, and 78 in 220 (35.45\%) cases had miR-126-low and CRK-high expression. More interestingly, the expression levels of miR-126 in gastric cancer tissues were significantly negatively correlated with those of CRK mRNA as determined by Spearman's correlation ( $r=-0.412$, $P<0.001$ ) (Figure 2C). 

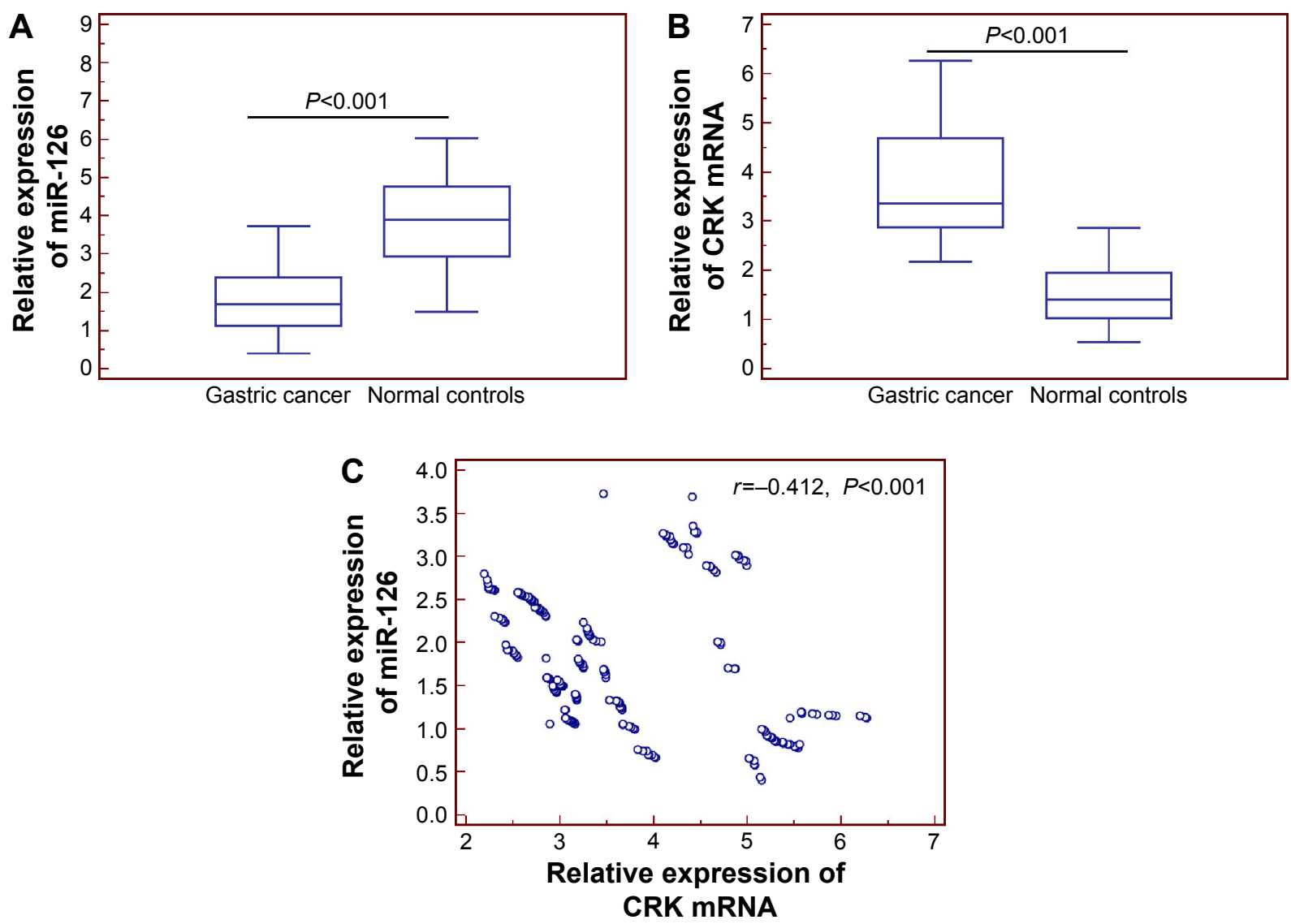

Figure 2 miR-126 and CRK mRNA expression levels were, respectively, decreased and increased in human gastric cancer tissues.

Notes: Relative expression of (A) miR-126 and (B) CRK mRNA in gastric cancer tissues and the matched normal gastric mucosa. (C) As determined by Spearman's correlation, the expression levels of miR-I 26 in gastric cancer tissues were significantly negatively correlated with those of CRK mRNA ( $r=-0.4 \mathrm{I} 2, P<0.00 \mathrm{I})$.

Abbreviation: CRK, CTIO oncogene homologue.

\section{Dysregulation of miR-I26/CRK axis} associates with aggressive progression in human gastric cancer

The associations between miR-126 and/or CRK expression levels and clinicopathological features of gastric cancer are summarized in Tables 2 and S1. The results revealed that low miR-126 expression and high CRK expression, alone or in combination, were all significantly associated with positive lymph node ( $P=0.01, P=0.01$, and $P=0.005$, respectively) and distant ( $P=0.008, P=0.008$, and $P=0.001$, respectively) metastases and advanced TNM stage (all $P<0.001)$ of patients with gastric cancer.

\section{Dysregulation of miR-126/CRK axis predicts poor prognosis in patients with gastric cancer}

Kaplan-Meier plots of overall survival curves stratified by miR-126 or CRK expression are, respectively, shown in Figure $3 \mathrm{~A}$ and B. A significant relationship was found between miR-126 expression and overall survival $(P=0.001$, log-rank test). In contrast, the overall survival ( $P=0.001$, log-rank test) of gastric cancer patients with high CRK expression was significantly shorter than in those with low CRK expression. Moreover, the chi-square value by log-rank (Mantel-Cox) indicated a significant difference among different groups with regard to the combined expression status of miR-126/CRK (Figure 3C). The results by pairwise comparisons showed that a statistically significant difference of overall survival existed between miR-126-low/CRK-high patients and any of the other two groups $(P<0.001)$. In all three groups, miR-126-low/ CRK-high patients had the worst prognosis.

A separate univariate analysis of the TNM stage IV group demonstrated that miR-126-low $(P=0.001)$, CRK-high $(P=0.001)$, and miR-126-low/CRK-high $(P<0.001)$ were all significantly associated with unfavorable overall survival (Figure 3D-F). In contrast, only combined miR-126/CRK expression was significantly associated with overall survival of patients in the TNM stage I-III group $(P=0.01$ ) (Figure $3 \mathrm{G}-\mathrm{I})$.

Table 3 shows the multivariate analyses of factors related to patient prognosis. Factors with possible prognostic effects 
Table 2 Association of miR-126 and/or CRK mRNA expression with the clinicopathological features of gastric cancer

\begin{tabular}{|c|c|c|c|c|c|c|c|}
\hline Features & $\begin{array}{l}\text { Number } \\
\text { of cases }\end{array}$ & $\begin{array}{l}\text { miR-1 26-low, } \\
\text { n (\%) }\end{array}$ & $P$-value & $\begin{array}{l}\text { CRK-high, } \\
\text { n (\%) }\end{array}$ & $P$-value & $\begin{array}{l}\text { miR-I26-low/ } \\
\text { CRK-high, n (\%) }\end{array}$ & $P$-value \\
\hline \multicolumn{8}{|l|}{ Age (years) ${ }^{\mathrm{a}}$} \\
\hline$\leq 55$ & 112 & $60(53.57)$ & 0.28 & $56(50.00)$ & 0.30 & $36(32.14)$ & 0.21 \\
\hline$>55$ & 108 & $58(53.70)$ & & $56(51.85)$ & & $42(38.89)$ & \\
\hline \multicolumn{8}{|l|}{ Sex ${ }^{a}$} \\
\hline Male & 160 & $86(53.75)$ & 0.26 & $80(50.00)$ & 0.22 & $58(36.25)$ & 0.22 \\
\hline Female & 60 & $32(53.33)$ & & $32(53.33)$ & & $20(33.33)$ & \\
\hline \multicolumn{8}{|l|}{ Tumor location ${ }^{b}$} \\
\hline Cardia & 30 & $16(53.33)$ & 0.15 & $15(50.00)$ & 0.18 & $10(33.33)$ & 0.29 \\
\hline Body & 82 & $50(60.98)$ & & $45(54.88)$ & & $30(36.59)$ & \\
\hline Antrum & 108 & $52(48.15)$ & & $52(48.15)$ & & $38(35.19)$ & \\
\hline \multicolumn{8}{|l|}{ Differentiation degree ${ }^{b}$} \\
\hline Well differentiated & 40 & $24(60.00)$ & 0.20 & $20(50.00)$ & 0.32 & $16(40.00)$ & 0.22 \\
\hline Moderately differentiated & 58 & $32(55.17)$ & & $30(51.72)$ & & $20(34.48)$ & \\
\hline Poorly differentiated & 122 & $62(50.82)$ & & $62(50.82)$ & & $42(34.43)$ & \\
\hline \multicolumn{8}{|l|}{ Depth of invasion ${ }^{\mathrm{a}}$} \\
\hline $\mathrm{TI} / \mathrm{T} 2$ & 71 & $42(59.15)$ & 0.11 & $42(59.15)$ & 0.09 & $28(39.44)$ & 0.13 \\
\hline $\mathrm{T} 3 / \mathrm{T} 4$ & 149 & $76(51.01)$ & & $70(46.98)$ & & $50(33.56)$ & \\
\hline \multicolumn{8}{|l|}{ Lymph node metastasis $^{b}$} \\
\hline No & 42 & $6(14.29)$ & 0.01 & $6(14.29)$ & 0.01 & $3(7.14)$ & 0.005 \\
\hline $\mathrm{NI}$ & 80 & $30(37.50)$ & & $28(35.00)$ & & $10(12.50)$ & \\
\hline N2 & 68 & $53(77.94)$ & & $50(73.53)$ & & $40(58.82)$ & \\
\hline N3 & 30 & $29(96.67)$ & & $28(93.33)$ & & $25(83.33)$ & \\
\hline \multicolumn{8}{|l|}{ Distant metastasis ${ }^{\mathrm{a}}$} \\
\hline MO & 190 & $88(46.32)$ & 0.008 & $82(43.16)$ & 0.008 & $48(25.26)$ & 0.001 \\
\hline MI & 30 & $30(100.00)$ & & $30(100.00)$ & & $30(100.00)$ & \\
\hline \multicolumn{8}{|l|}{ TNM stage $^{\mathrm{b}}$} \\
\hline 1 & 65 & $0(0)$ & $<0.001$ & $0(0)$ & $<0.001$ & $0(0)$ & $<0.001$ \\
\hline II & 15 & $6(40.00)$ & & $2(13.33)$ & & $2(13.33)$ & \\
\hline III & 20 & $12(60.00)$ & & $12(60.00)$ & & $6(30.00)$ & \\
\hline IV & 120 & $100(76.67)$ & & $98(81.67)$ & & $70(58.33)$ & \\
\hline
\end{tabular}

Notes: aFisher's exact test was used to evaluate the association of miR-126 and/or CRK expression with the patients' age ( $\leq 55$ vs $>55$ years), sex (male vs female), depth

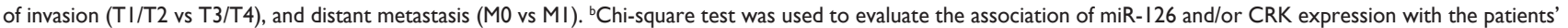
tumor location, differentiation degree, lymph node metastasis, and TNM stage.

Abbreviation: CRK, CTIO oncogene homologue.

in gastric cancer were analyzed by Cox regression analysis. The results revealed that lymph node metastases $(P=0.02)$, distant metastases $(P=0.02)$, TNM stage $(P=0.01)$, miR-126 expression $(P=0.01)$, CRK expression $(P=0.01)$, and miR$126 / C R K$ combined expression $(P=0.001)$ were independent prognostic factors of patients with gastric cancer. However, age, sex, tumor differentiation, and depth of tumor invasion had no prognostic value.

A separate multivariate analysis of the TNM stage IV group demonstrated that miR-126 expression, CRK expression, and miR-126/CRK expression were all independent prognostic factors of patients with TNM stage IV gastric cancer (all $P<0.05$ ) (Table 4), but not for those with TNM stage I-III (all $P>0.05$ ) (data not shown).

\section{Discussion}

Gastric cancer remains a major cause of morbidity and mortality worldwide, thus there is a clear need to search for more efficient molecular markers for diagnosis and prognosis in this disease. miRNAs are a recently discovered category of small RNA molecules that regulate gene expression posttranscriptionally. Growing evidence shows that miRNAs are aberrantly expressed in a variety of human cancers and crucial to tumorigenesis. ${ }^{10} \mathrm{We}$ herein provide the evidence that miR-126 and CRK mRNA expression levels were, respectively, decreased and increased in gastric cancer tissues compared with the matched normal gastric mucosa. We found that low miR-126 and high CRK expression levels, alone or in combination, were all significantly associated with aggressive progression and patients' poor prognosis in gastric cancer. More interestingly, the aberrant expression levels of miR-126 and CRK mRNA were both observed from early- to advanced-stage gastric cancer and were closely correlated with lymph node and distant metastases. These data imply that miR-126/CRK axis in gastric cancer may play an important role in the process 

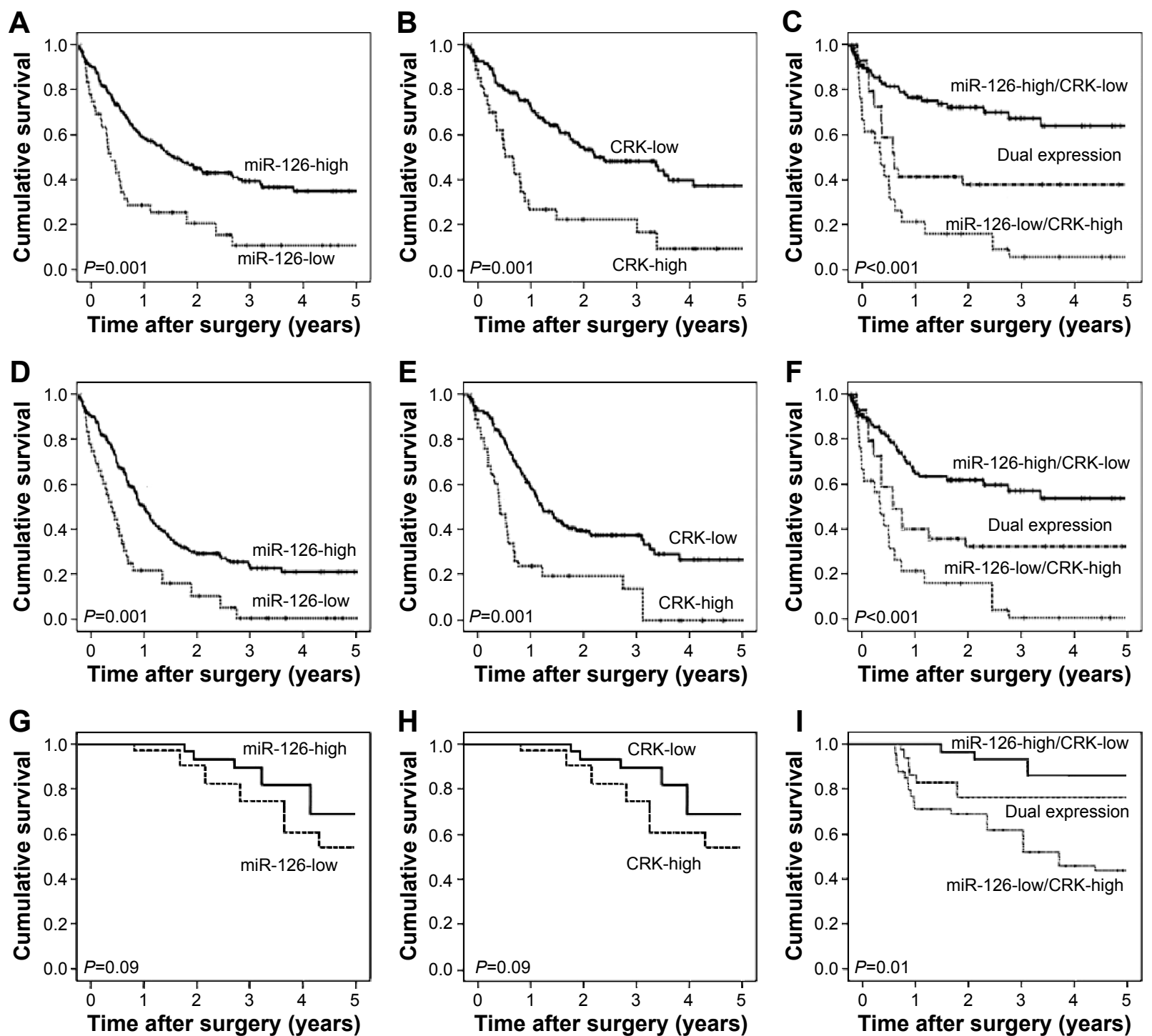

Figure 3 Overall survival curves for gastric cancer patients.

Notes: (A-C) Overall survival curves for two groups defined by low and high expression of miR-I26 or CRK mRNA and for four groups defined by combined expression of miR-126 and CRK in gastric cancer. (D-F) Overall survival curves for two groups defined by low and high expression of miR-I26 or CRK mRNA and for four groups defined by combined expression of miR-I26 and CRK in gastric cancer with TNM stage IV. (G-I) Overall survival curves for two groups defined by low and high expression of miR-I26 or CRK mRNA and for four groups defined by combined expression of miR-I26 and CRK in gastric cancer with TNM stage I-III. "Dual expression" refers to patients with miR-126-low/CRK-low plus patients with miR-I26-high/CRK-high.

Abbreviation: CRK, CTIO oncogene homologue.

Table 3 Multivariate analyses of prognostic factors in gastric cancer

\begin{tabular}{llll}
\hline Independent factors & Multivariate P-value & Hazard ratio & 95\% confidence interval \\
\hline Age ( $\leq 55$ vs $>55$ years) & 0.23 & 1.26 & $0.73-2.20$ \\
Sex (male vs female) & 0.20 & 1.35 & $0.77-2.35$ \\
Tumor location (cardia and body vs antrum) & 0.18 & 1.68 & $0.89-3.82$ \\
Differentiation degree (well and moderately & 0.26 & 1.18 & $0.48-2.95$ \\
differentiated vs poorly differentiated) & & & $1.01-2.28$ \\
Depth of invasion (TI/T2 vs T3/T4) & 0.21 & 1.42 & $1.03-18.92$ \\
Lymph node metastasis (N0/NI vs N2/N3) & 0.02 & 4.17 & $1.06-19.18$ \\
Distant metastasis (MO vs MI) & 0.02 & 4.28 & $1.09-19.63$ \\
TNM stage (I-II vs III-IV) & 0.01 & 4.76 & $1.01-16.32$ \\
miR-I26 expression (low vs high) & 0.01 & 4.28 & $1.10-20.26$ \\
CRK expression (low vs high) & 0.01 & 4.79 & $1.89-26.88$ \\
miR-I26/CRK expression (low/high vs low/low, & 0.001 & 9.80 & \\
high/low, and high/high) & & &
\end{tabular}

Abbreviation: CRK, CTIO oncogene homologue. 
Table 4 Multivariate analyses of prognostic factors in gastric cancer with TNM stage IV

\begin{tabular}{llll}
\hline Independent factors & Multivariate P-value & Hazard ratio & 95\% confidence interval \\
\hline Age ( $\leq 55$ vs $>55$ years) & 0.18 & 1.68 & $0.69-3.22$ \\
Sex (male vs female) & 0.17 & 1.62 & $0.81-3.88$ \\
Tumor location (cardia and body vs antrum) & 0.20 & 2.06 & $0.82-4.32$ \\
Differentiation degree (well and moderately & 0.23 & 2.18 & $0.88-4.60$ \\
differentiated vs poorly differentiated) & & & \\
Depth of invasion (TI/T2 vs T3/T4) & 0.28 & 2.89 & $0.93-5.27$ \\
Lymph node metastasis (N0/NI vs N2/N3) & 0.00 I & 6.32 & $2.66-20.98$ \\
Distant metastasis (M0 vs MI) & 0.001 & 6.56 & $2.98-22.32$ \\
miR-I26 expression (low vs high) & 0.00 I & 6.82 & $3.01-22.96$ \\
CRK expression (low vs high) & 0.00 I & 6.96 & $3.13-23.02$ \\
miR-I26/CRK expression (low/high vs & $<0.001$ & 11.28 & $3.89-30.86$ \\
low/low, high/low, and high/high) & & &
\end{tabular}

Abbreviation: CRK, CTIO oncogene homologue.

of tumor initiation and dissemination of cancer cells to distant organs.

miR-126, which is mapped within its host gene EGFL-7 and is highly expressed in vascular endothelial cells, has been reported to be a tumor suppressor in various human cancer types. ${ }^{27-32}$ For example, Jia et al ${ }^{27}$ found that restoration of miR-126 levels attenuated the invasive potential of bladder cancer cells through its ability to target ADAM9; Yang et al ${ }^{28}$ identified the tumor suppressive effect of miR-126 on oral squamous cell carcinoma in vitro; Sun et a ${ }^{31}$ indicated that miR-126 was able to inhibit laryngeal squamous cell carcinoma partly by suppressing Camsap 1 expression which could induce microtubule formation and aggregation; and Guo et $\mathrm{al}^{29}$ noted loss of miR-126 expression in colon cancer cell lines when compared to normal human colon epithelia and revealed that miR-126 regulated PI3K signaling partly by targeting p85b. Similarly, miR-126 has been demonstrated to suppress tumor invasion and metastasis of gastric cancer via regulating many target genes, including CRK. ${ }^{20-23}$ In the current study, we paid special attention to the clinical significance of miR-126/CRK axis in human gastric cancer. At first, we confirmed the aberrant expression of miR-126 and CRK mRNA in gastric cancer tissues. Consistently, miR-126 downregulation has been observed in various cancer types, including oral squamous cell cancer, breast cancer, non-small-cell lung cancer, prostate cancer, and renal cell carcinoma, ${ }^{27-32}$ and CRK overexpression has also been found in cancerous epithelial cells of breast, lung, oral, or head and neck origin, leading to the enhancement of epithelial-tomesenchymal transitions, characterized by the breakdown of adherens junctions, enhanced cell dispersal, and remodeling of cortical actin. ${ }^{33,34}$ In addition, the associations of miR-126 and/or CRK expression with clinicopathological features were also analyzed. Our data demonstrated that low miR-126 expression and high CRK expression, alone or in combination, were all significantly associated with positive metastasis and advanced tumor stage. According to the previous study of Li et al, ${ }^{24}$ miR-126 was significantly related with histologic differentiation, which was not in line with our data. The reason for this difference might be the heterogeneity of different patient cohorts. We further observed that miR-126 might be a favorable prognostic factor; in contrast, CRK might be considered an oncogene associated with poor prognosis in human gastric cancer. Li et a $1^{16}$ previously identified a seven-miRNA signature (miR-10b, miR-21, miR-223, miR-338, let-7a, miR-30a-5p, miR-126) for overall survival and relapse-free survival of gastric cancer patients. However, the prognostic impact of miR-126 was larger than in the previous studies ${ }^{16}$ due to the heterogeneity of different patient cohorts. Moreover, an emerging body of evidence suggests that the aberrant expression of miR-126 and CRK correlates with prognosis in various other human cancers. For example, Donnem et al ${ }^{30}$ identified miR-126 as a strong and independent negative prognostic factor in non-small-cell lung cancer, and its prognostic impact might be related primarily to histology and nodal status; Liu et al ${ }^{132}$ indicated that miR-126 was an independent prognostic factor for overall survival, suggesting its clinical significance as a prognostic predictor in colorectal cancer patients. More importantly, in the current study, patients with miR-126 downregulation in combination with CRK upregulation had a worse overall survival than all of the other patients, and the prognostic potential of combined miR-126/CRK expression was better than the two markers alone.

\section{Conclusion}

The findings of the current study suggest that miR-126 and CRK combined expression may serve as an independent predictor of overall survival in patients with advanced gastric 
cancer. Detection of their combined expression might be particularly helpful for surveillance of disease progression and treatment stratification.

\section{Disclosure}

The authors report no conflicts of interest in this work.

\section{References}

1. Torre LA, Bray F, Siegel RL, Ferlay J, Lortet-Tieulent J, Jemal A. Global cancer statistics, 2012. CA Cancer J Clin. 2015;65:87-108.

2. Zhang YZ, Zhang LH, Gao Y, et al. Discovery and validation of prognostic markers in gastric cancer by genome-wide expression profiling. World J Gastroenterol. 2011;17:1710-1717.

3. Ye YW, Dong RZ, Zhou Y, et al. Prognostic analysis of familial gastric cancer in Chinese population. J Surg Oncol. 2011;104:76-82.

4. Wang CS, Hsieh CC, Chao TC, et al. Resectable gastric cancer: operative mortality and survival analysis. Chang Gung Med J. 2002; 25:216-227.

5. Pasechnikov V, Chukov S, Fedorov E, Kikuste I, Leja M. Gastric cancer: prevention, screening and early diagnosis. World J Gastroenterol. 2014; 20:13842-13862.

6. Cervantes A, Rodríguez Braun E, Pérez Fidalgo A, Chirivella González I. Molecular biology of gastric cancer. Clin Transl Oncol. 2007;9: 208-215.

7. Yang W, Raufi A, Klempner SJ. Targeted therapy for gastric cancer: molecular pathways and ongoing investigations. Biochim Biophys Acta. 2014;1846:232-237.

8. Huang JT, Wang J, Srivastava V, Sen S, Liu SM. MicroRNA machinery genes as novel biomarkers for cancer. Front Oncol. 2014;4:113.

9. Palanichamy JK, Rao DS. miRNA dysregulation in cancer: towards a mechanistic understanding. Front Genet. 2014;5:54.

10. Farooqi AA, Rehman ZU, Muntane J. Antisense therapeutics in oncology: current status. Onco Targets Ther. 2014;7:2035-2042.

11. Uozaki H, Morita S, Kumagai A, et al. Stromal miR-21 is more important than miR-21 of tumour cells for the progression of gastric cancer. Histopathology. 2014;65:775-783.

12. Tsujiura M, Komatsu S, Ichikawa D, et al. Circulating miR-18a in plasma contributes to cancer detection and monitoring in patients with gastric cancer. Gastric Cancer. 2015;18:271-279.

13. Mu YP, Tang S, Sun WJ, Gao WM, Wang M, Su XL. Association of miR-193b down-regulation and miR-196a up-regulation with clinicopathological features and prognosis in gastric cancer. Asian Pac J Cancer Prev. 2014;15:8893-8900.

14. Zhou X, Xia Y, Su J, Zhang G. Down-regulation of miR-141 induced by helicobacter pylori promotes the invasion of gastric cancer by targeting STAT4. Cell Physiol Biochem. 2014;33:1003-1012.

15. Fei B, Wu H. MiR-378 inhibits progression of human gastric cancer MGC-803 cells by targeting MAPK1 in vitro. Oncol Res. 2012;20: $557-564$.

16. Li X, Zhang Y, Zhang Y, Ding J, Wu K, Fan D. Survival prediction of gastric cancer by a seven-microRNA signature. Gut. 2010;59: $579-585$.
17. Wang S, Aurora AB, Johnson BA, et al. The endothelial-specific microRNA miR-126 governs vascular integrity and angiogenesis. Dev Cell. 2008;15:261-271.

18. Shen WF, Hu YL, Uttarwar L, Passegue E, Largman C. MicroRNA-126 regulates HOXA9 by binding to the homeobox. Mol Cell Biol. 2008; 28:4609-4619.

19. Fish JE, Santoro MM, Morton SU, et al. miR-126 regulates angiogenic signaling and vascular integrity. Dev Cell. 2008;15:272-284.

20. Feng R, Chen X, Yu Y, et al. miR-126 functions as a tumour suppressor in human gastric cancer. Cancer Lett. 2010;298:50-63.

21. Otsubo T, Akiyama Y, Hashimoto Y, Shimada S, Goto K, Yuasa Y. MicroRNA-126 inhibits SOX2 expression and contributes to gastric carcinogenesis. PLoS One. 2011;6:e16617.

22. Wang J, Chen X, Li P, et al. CRKL promotes cell proliferation in gastric cancer and is negatively regulated by miR-126. Chem Biol Interact. 2013;206:230-238.

23. Liu LY, Wang W, Zhao LY, et al. Mir-126 inhibits growth of SGC-7901 cells by synergistically targeting the oncogenes PI3KR2 and Crk, and the tumor suppressor PLK2. Int J Oncol. 2014;45:1257-1265.

24. Li X, Wang F, Qi Y. MiR-126 inhibits the invasion of gastric cancer cell in part by targeting Crk. Eur Rev Med Pharmacol Sci. 2014;18: 2031-2037.

25. Marano L, Boccardi V, Braccio B, et al. Comparison of the 6th and 7th editions of the AJCC/UICC TNM staging system for gastric cancer focusing on the "N" parameter-related survival: the monoinstitutional NodUs Italian study. World J Surg Oncol. 2015;13:215.

26. Zhang TC, Zhu WG, Huang MD, Fan RH, Chen XF. Prognostic value of ADAM17 in human gastric cancer. Med Oncol. 2012;29:2684-2690.

27. Jia AY, Castillo-Martin M, Bonal DM, Sánchez-Carbayo M, Silva JM, Cordon-Cardo C. MicroRNA-126 inhibits invasion in bladder cancer via regulation of ADAM9. Br J Cancer. 2014;110:2945-2954.

28. Yang X, Wu H, Ling T. Suppressive effect of microRNA-126 on oral squamous cell carcinoma in vitro. Mol Med Rep. 2014;10:125-130.

29. Guo C, Sah JF, Beard L, Willson JK, Markowitz SD, Guda K. The noncoding RNA, miR-126, suppresses the growth of neoplastic cells by targeting phosphatidylinositol 3-kinase signaling and is frequently lost in colon cancers. Genes Chromosomes Cancer. 2008;47:939-946.

30. Donnem T, Lonvik K, Eklo K, et al. Independent and tissue-specific prognostic impact of miR-126 in nonsmall cell lung cancer: coexpression with vascular endothelial growth factor-A predicts poor survival. Cancer. 2011;117:3193-3200.

31. Sun X, Wang ZM, Song Y, Tai XH, Ji WY, Gu H. MicroRNA-126 modulates the tumor microenvironment by targeting calmodulin-regulated spectrin-associated protein 1 (Camsap1). Int J Oncol. 2014;44: $1678-1684$.

32. Liu Y, Zhou Y, Feng X, et al. Low expression of microRNA-126 is associated with poor prognosis in colorectal cancer. Genes Chromosomes Cancer. 2014;53:358-365.

33. Bell ES, Park M. Models of crk adaptor proteins in cancer. Genes Cancer. 2012;3:341-352.

34. Sriram G, Birge RB. Emerging roles for crk in human cancer. Genes Cancer. 2010;1:1132-1139. 


\section{Supplementary material}

Table SI Association of miR-I26-high, CRK-low, and miR-126-high/CRK-low expression with the clinicopathological features of gastric cancer

\begin{tabular}{|c|c|c|c|c|c|c|c|}
\hline Features & $\begin{array}{l}\text { Number } \\
\text { of cases }\end{array}$ & $\begin{array}{l}\text { miR- I 26-high, } \\
\text { n (\%) }\end{array}$ & $P$-value & $\begin{array}{l}\text { CRK-low, } \\
\text { n (\%) }\end{array}$ & $P$-value & $\begin{array}{l}\text { miR-I 26-high/ } \\
\text { CRK-low, n (\%) }\end{array}$ & $P$-value \\
\hline \multicolumn{8}{|l|}{ Age (years) } \\
\hline$\leq 55$ & 112 & $52(46.43)$ & 0.26 & $56(50.00)$ & 0.29 & $31(27.68)$ & 0.20 \\
\hline$>55$ & 108 & $50(46.30)$ & & $52(48.15)$ & & $37(34.26)$ & \\
\hline \multicolumn{8}{|l|}{ Sex } \\
\hline Male & 160 & $74(46.25)$ & 0.26 & $80(50.00)$ & 0.22 & $53(33.13)$ & 0.20 \\
\hline Female & 60 & $28(46.67)$ & & $28(46.67)$ & & $15(25.00)$ & \\
\hline \multicolumn{8}{|l|}{ Tumor location } \\
\hline Cardia & 30 & $14(46.67)$ & 0.16 & $15(50.00)$ & 0.19 & $8(26.67)$ & 0.28 \\
\hline Body & 82 & $32(39.02)$ & & $37(45.12)$ & & $26(3 \mid .7 I)$ & \\
\hline Antrum & 108 & $56(51.85)$ & & $56(5 \mathrm{I} .85)$ & & $34(31.48)$ & \\
\hline \multicolumn{8}{|l|}{ Differentiation degree } \\
\hline Well differentiated & 40 & $16(40.00)$ & 0.21 & $20(50.00)$ & 0.33 & $14(35.00)$ & 0.21 \\
\hline Moderately differentiated & 58 & $26(44.83)$ & & $28(48.28)$ & & $18(31.03)$ & \\
\hline Poorly differentiated & 122 & $60(49.18)$ & & $60(49.18)$ & & $36(29.5 I)$ & \\
\hline \multicolumn{8}{|l|}{ Depth of invasion } \\
\hline $\mathrm{TI} / \mathrm{T} 2$ & 71 & $29(40.85)$ & 0.12 & $29(40.85)$ & 0.09 & $23(32.39)$ & 0.21 \\
\hline $\mathrm{T} 3 / \mathrm{T} 4$ & 149 & 73 (48.99) & & $79(53.02)$ & & $45(30.20)$ & \\
\hline \multicolumn{8}{|l|}{ Lymph node metastasis } \\
\hline No & 42 & $36(85.7 I)$ & 0.01 & $36(85.7 I)$ & 0.01 & $33(78.57)$ & 0.008 \\
\hline $\mathrm{NI}$ & 80 & $50(62.50)$ & & $52(65.00)$ & & $23(28.75)$ & \\
\hline N2 & 68 & $15(22.06)$ & & 18 (26.47) & & $10(\mid 4.7 I)$ & \\
\hline N3 & 30 & I (3.33) & & $2(6.67)$ & & $2(6.67)$ & \\
\hline \multicolumn{8}{|l|}{ Distant metastasis } \\
\hline Mo & 190 & $102(53.68)$ & 0.008 & $108(56.84)$ & 0.008 & $63(33.16)$ & 0.03 \\
\hline MI & 30 & $0(0.00)$ & & $0(0.00)$ & & $5(16.67)$ & \\
\hline \multicolumn{8}{|l|}{ TNM stage } \\
\hline 1 & 65 & $65(100.00)$ & $<0.001$ & $65(100.00)$ & $<0.001$ & $50(76.92)$ & 0.01 \\
\hline II & 15 & $9(60.00)$ & & $13(86.67)$ & & $8(53.33)$ & \\
\hline III & 20 & $8(40.00)$ & & $8(40.00)$ & & $5(25.00)$ & \\
\hline IV & 120 & $20(23.33)$ & & $22(18.33)$ & & $5(4.17)$ & \\
\hline
\end{tabular}

Abbreviation: CRK, CTIO oncogene homologue.

\section{Publish your work in this journal}

OncoTargets and Therapy is an international, peer-reviewed, open access journal focusing on the pathological basis of all cancers, potential targets for therapy and treatment protocols employed to improve the management of cancer patients. The journal also focuses on the impact of management programs and new therapeutic agents and protocols on patient perspectives such as quality of life, adherence and satisfaction. The manuscript management system is completely online and includes a very quick and fair peer-review system, which is all easy to use. Visit http://www.dovepress.com/testimonials.php to read real quotes from published authors. 